Article

\title{
Investigation on the Torque Ripple Reduction Method of a Hybrid Electric Vehicle Motor
}

\author{
Hyungkwan Jang ${ }^{1}\left(\mathbb{D}\right.$, Hyunwoo Kim $\left.{ }^{1}{ }^{(}\right)$, Huai-Cong Liu ${ }^{2}$, Ho-Joon Lee ${ }^{3}$ and Ju Lee $^{1, *}$ \\ 1 Department of Electrical Engineering, Hanyang University, Seoul 04763, Korea; \\ jhkinhyu@hanyang.ac.kr (H.J.); khw7481@hanyang.ac.kr (H.K.) \\ 2 EPS Engineering Design Team, Hyundai Transys, Hwaseong 18280, Korea; hcliu@hyundai-transys.com \\ 3 Division of Converged Electronic Engineering, Cheongju University, Cheongju 28503, Korea; hjlee@cju.ac.kr \\ * Correspondence: julee@hanyang.ac.kr; Tel.: +82-2-2220-0342
}

Citation: Jang, H.; Kim, H.; Liu,

H.-C.; Lee, H.-J.; Lee, J. Investigation on the Torque Ripple Reduction Method of a Hybrid Electric Vehicle Motor. Energies 2021, 14, 1413.

https://doi.org/10.3390/en14051413

Academic Editor: Sung Gu Lee

Received: 26 January 2021

Accepted: 2 March 2021

Published: 4 March 2021

Publisher's Note: MDPI stays neutral with regard to jurisdictional claims in published maps and institutional affiliations.

Copyright: (c) 2021 by the authors. Licensee MDPI, Basel, Switzerland. This article is an open access article distributed under the terms and conditions of the Creative Commons Attribution (CC BY) license (https:// creativecommons.org/licenses/by/ $4.0 /)$.

\begin{abstract}
Owing to the development of electric vehicles (EVs), research and development are underway to minimize torque ripple in relation to vibration and noise in EV motors. Although there are various ways to reduce torque ripple, this study analyzes the torque ripple, cogging torque, total harmonic distortion (THD), and magnetic flux density distribution for the three rotor shapes of interior permanent magnet synchronous motors, which are widely employed in EVs. To reduce the torque ripple while retaining the required average torque, the barrier shape is optimized, and wedge skew is applied. First, regarding the rotor barrier shape, torque ripple is primarily reduced by designing the rotor barrier shape with the response surface method, which is an experimental design method. Additionally, the wedge skew shape considering the bidirectional rotation and fabrication was applied to the stator shoe as a step and analyzed using three-dimensional finite element analysis. When designing the wedge skew, the layer subdivision according to the axial length, wedge skew diameter, and wedge skew position was analyzed and improved. The torque ripple reduction method in this paper can be applied not only to motors for EVs or Hybrid EVs (HEVs) but also all types of permanent magnet synchronous motors.
\end{abstract}

Keywords: torque ripple; cogging torque; interior permanent magnet synchronous motors; total harmonic distortion; electric vehicle; magnetic flux density saturation

\section{Introduction}

In recent years, research and development in electric motors for electric vehicles (EVs) have been actively conducted. The minimum and maximum numbers of electric motors for EVs are 50 and 150, respectively. Vehicles equipped with traction motors can be largely divided into EVs and hybrid EVs (HEVs). If the internal combustion engine and traction motor are installed together, it is an HEV. On the other hand, if a car is driven only by a motor, it is an EV. In addition, according to the battery capacity, they are divided into micro HEVs, mild HEVs, full HEVs, plug-in HEVs, and EVs. In other words, the higher the dependence of the automobile motors on the battery, the larger the battery capacity and the lower the fuel consumption. As shown in Figure 1, electric motors for EVs are classified from $\mathrm{P} 0$ to $\mathrm{P} 4$ according to the mounting position [1]. The minimum capacity from $\mathrm{P} 0$ to P5 is over $15 \mathrm{~kW}$.

Interior permanent magnet synchronous motors (IPMSMs) are widely employed in EVs due to their high power density [2,3]. IPMSMs can operate in a wide speed range with weakening magnetic flux control operation and have the advantage of a higher efficiency than induction motors and wound field synchronous motors [4-8].

For motors for EVs or HEVs, torque ripple, which could be one of the sources of vibration and acoustic noise, must be minimized [9-11]. In the case of P0 and P1 installed in the front of the clutch, the vibration and acoustic noise transmitted to the passenger may be weakened by the engine vibration and the flywheel of the clutch. However, P2 P5 
are mounted on the rear part of the clutch, which can greatly affect passenger comfort. Total harmonic distortion (THD) of no-load back electromotive force (back-EMF) is one of the causes of torque ripple [12-14]. In addition, when magnetic flux saturation occurs in the stator or rotor, the torque ripple increases nonlinearly [15,16]; thus, a magnetic flux saturation prevention design is needed to reduce torque ripple. The torque ripple is also related to the cogging torque that is generated in the no-load condition, and research is being conducted to reduce torque ripple and cogging torque for safe motor operation [17].

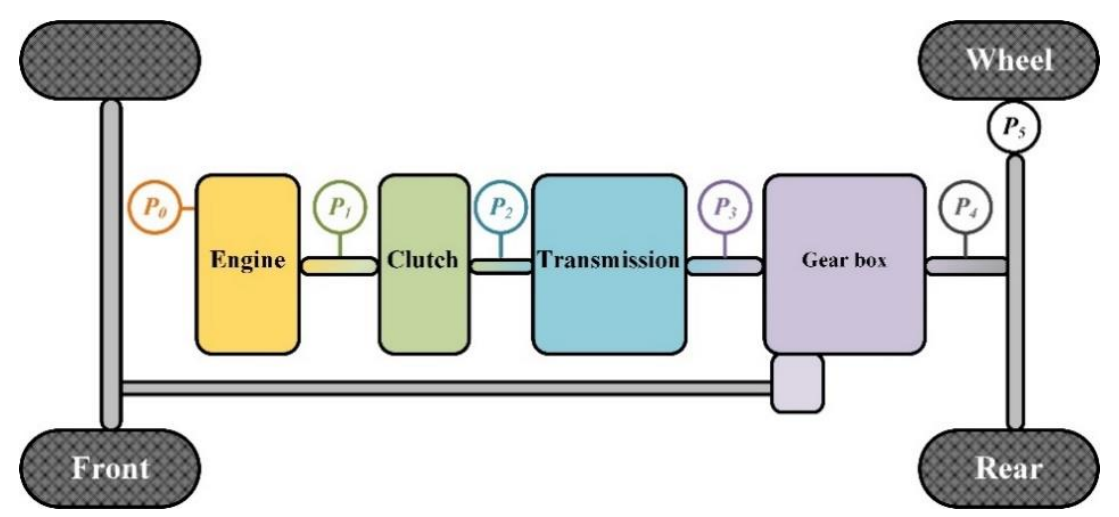

Figure 1. Topological diagrams of motors for a hybrid electric vehicle (HEV).

Methods for reducing torque ripple include rotor shape design or motor control [18-20]. However, in the case of a slot-less motor, no such problem exists as the cogging torque is quite small due to the characteristics of the stator structure [21]. Although torque ripple can be reduced by motor control, torque ripple reduction by motor design is deemed better in terms of reliability and performance.

Characteristics of torque ripple, cogging torque, and no-load back-EMF THD vary according to the combination of the number of stator slots and the number of rotor poles. The combination of the number of stator slots and the number of rotor poles is divided into integer slot winding and fractional slot winding. The integer slot winding means that the number of slots divided by number of poles is an integer. If the number of slots divided by the number of poles is not an integer, it is a fractional slot winding. According to [22], higher cogging torque occurs in integer slot winding compared to fractional slot winding. In other words, in fractional slot winding, relatively low torque ripple can be expected [23,24]. Furthermore, fractional slot winding has a high power density and a short end coil structure; therefore, the efficiency is improved by minimizing copper loss $[25,26]$. It is also very advantageous when applied to EVs because it has excellent fault diagnosis characteristics due to nonoverlapping end coils [27,28]. Although the fractional slot winding can generate a large magnetomotive force (MMF) due to the nature of the concentrated winding, it has the disadvantage of large spatial harmonics $[29,30]$. There are two main methods to reduce spatial harmonics. The first is to apply skew to the stator or rotor. Second, there is a method of optimizing the shape of the rotor. However, in this study, a novel method of applying wedge skew to the stator is proposed to reduce the torque ripple.

A 12-pole 18-slot fractional slot winding was used to minimize the torque ripple for HEV motors. In Section 2, torque ripple characteristics are analyzed for the bar-type, U-type, and V-type, which are the representative shapes of the IPMSM. In Section 3, the rotor barrier shape was optimized using the response surface methodology (RSM), which is an experimental design method. In Section 4, wedge skew to stator shoe is investigated with design parameters to reduce torque ripple while retaining the required average torque. In addition, this study was conducted to minimize torque ripple while considering the manufacturability of the motor in designing the wedge skew. 


\section{Analysis of Torque Ripple Characteristics by Various Rotor Shapes}

The torque characteristics employed for HEVs were compared and analyzed for the bar-type, U-type, and V-type IPMSMs. A 12-pole rotor and an 18-slot stator, which is a fractional slot winding, were adopted. The fractional slot winding has the advantage of a lower cogging torque than an integer slot winding. Figure 2 shows the shape of the bar-type, U-type, and V-type IPMSMs. When comparing the three rotor types, the shapes of the stator, the input current, voltage limit, stack length, and air gap distance were the same. In the case of a permanent magnet, the thickness of the permanent magnet was $6 \mathrm{~mm}$, and the permanent magnet usage was the same as that shown in Table 1. It also shows the main dimensions of the three types of IPMSM. The rated average torque and rated speed of the motor are $106.5 \mathrm{Nm}$ and $1350 \mathrm{rpm}$, respectively, and the capacity is $15 \mathrm{~kW}$. In addition, the maximum speed is $5000 \mathrm{rpm}$ and the required average torque is $29 \mathrm{Nm}$. The design constraints are a phase voltage limit of $46.7 \mathrm{~V}_{\mathrm{ph}}$, an input current of $300 \mathrm{~A}_{\text {peak, }}$ and a torque ripple within $15 \%$.

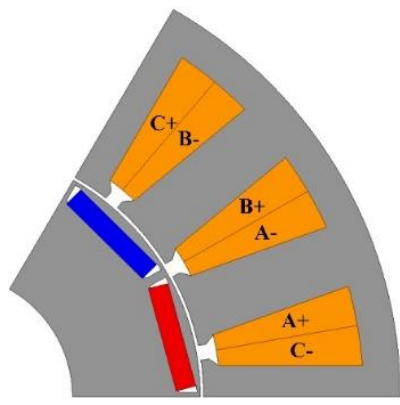

(a)

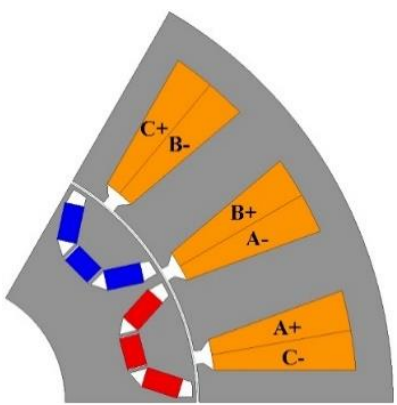

(b)

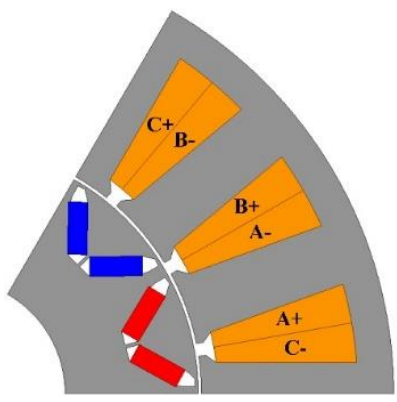

(c)

Figure 2. A $1 / 6$ periodic model of a $15 \mathrm{~kW} \mathrm{HEV} \mathrm{motor.} \mathrm{(a)} \mathrm{Bar-type} \mathrm{interior} \mathrm{permanent} \mathrm{magnet}$ synchronous motor (IPMSM); (b) U-type IPMSM; (c) V-type IPMSM.

Table 1. Specification of electric motors.

\begin{tabular}{ccc}
\hline Item & Value & Unit \\
\hline Stator diameter & 270 & $\mathrm{~mm}$ \\
Rotor diameter & 151 & $\mathrm{~mm}$ \\
Air gap length & 1 & $\mathrm{~mm}$ \\
Stack length & 74 & $\mathrm{~mm}$ \\
Area of permanent magnet & 192 & $\mathrm{~mm}^{2}$ \\
Number of poles & 12 & - \\
Number of slots & 18 & - \\
\hline
\end{tabular}

Figure 3 shows the torque and cogging torque waveform according to the rotor shape. In designing the three types of rotor, the rotor is designed to reduce torque ripple and cogging torque while satisfying the required average torque. From Equation (1), the torque ripple is generated with periodicity by the stator and rotor MMFs [18].

$$
T_{\text {ripple }}=-\frac{P}{2} \frac{\mu_{0}}{g} r_{g} l_{\text {stk }} \pi \sum_{\substack{h=6 m \mp 1 \\ m=1,2,3 \ldots}}\left(h f_{s, h} f_{r, h} \sin \left((h \pm 1) \omega_{e} t \pm \gamma_{d}\right)\right)
$$

where $P$ is the number of poles, $\mu_{0}$ is the air permeability $(\mathrm{H} / \mathrm{m}), r_{g}$ is the air gap radius $(\mathrm{mm}), f_{s, h}$ is the $h$ th-order stator MMF (A.T), $f_{r, h}$ is the $h$ th-order rotor MMF (A-T), and $\gamma$ is the phase angle (degree) between the $d$-axis and $i_{a}$. 


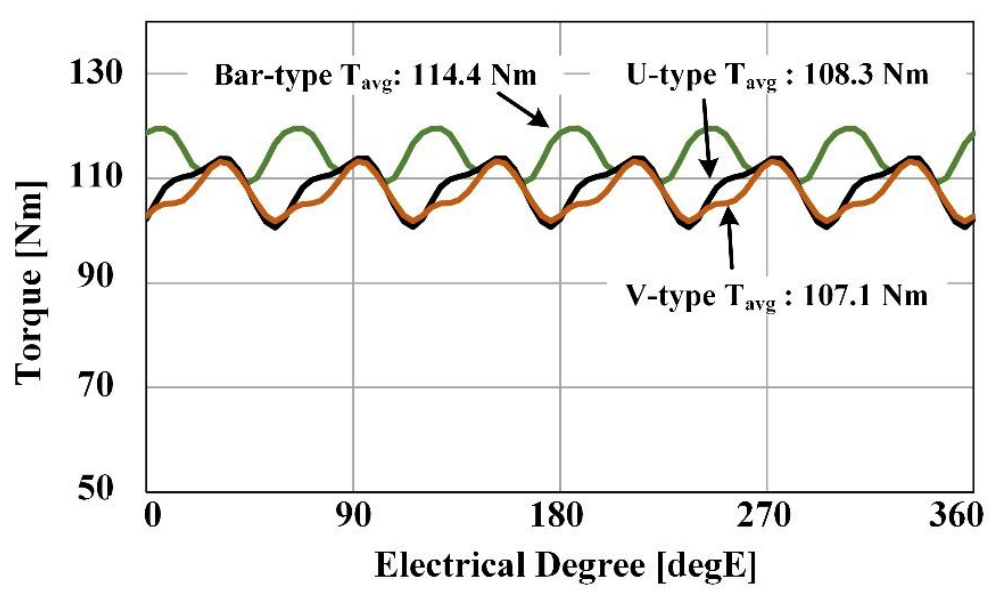

(a)

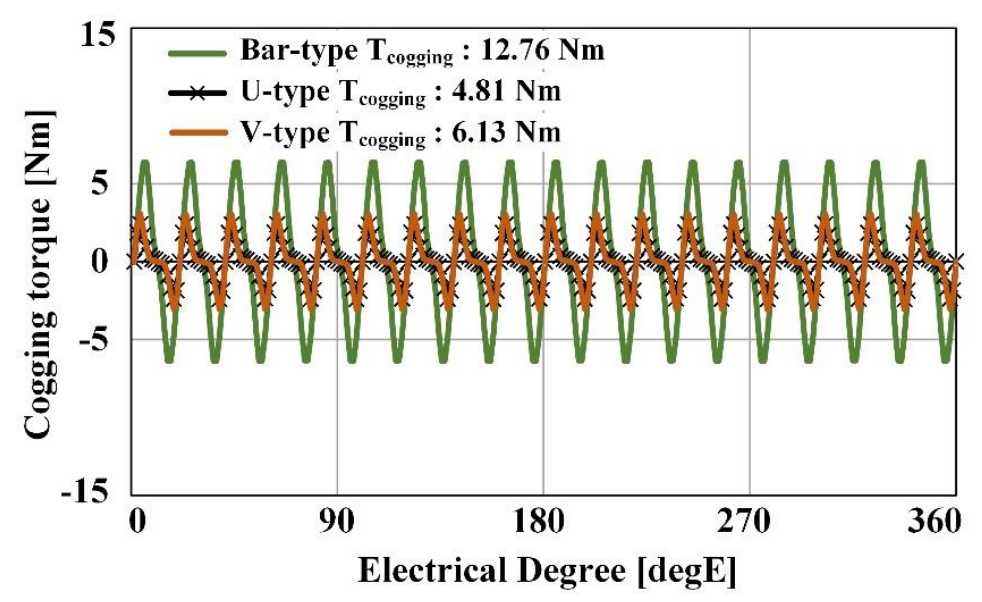

(b)

Figure 3. Wave form of three types of motors. (a) Torque; (b) cogging torque.

As the stator MMF is determined by the current and number of turns, the spatial distribution by the magnetic reluctance characteristic is immediately inferred. The MMF of the rotor is determined by the permanent magnet, and the spatial distribution is inferred by the barrier shape. MMF due to the barrier shape of the rotor is expressed as follows:

$$
f_{r}=\sum_{h \neq 2,4, \cdots} f_{r, h} \cos (h \theta)
$$

The maximum average torque per ampere was determined from the rated speed of each rotor shape. The current phase for the bar-type is $22^{\circ}$, the current phase for the U-type is $27^{\circ}$, and the current phase for the V-type is $28^{\circ}$. The bar-type can generate higher average torque, but the torque ripple is $9.12 \%$ and the V-type torque ripple is $10.73 \%$, which is a small difference. More importantly, as shown in Table 2, it can be seen that the tendency of cogging torque and torque ripple is different. The bar-type cogging torque is worse than the V-type cogging torque. In the case of the U-type rotor, even if the cogging torque is the lowest among the three types of rotors, the torque ripple of the U-type is $12.20 \%$, which is the severest torque ripple among the three types of models. In this study, the torque ripple was calculated using Equation (3). 
Table 2. Comparison of torque ripple and cogging torque at $1350 \mathrm{rpm}$.

\begin{tabular}{ccc}
\hline Type & Torque Ripple & Cogging Torque (Peak to Peak) \\
\hline Bar-type IPMSM & $9.12 \%$ & $12.76 \mathrm{Nm}$ \\
U-type IPMSM & $12.20 \%$ & $4.81 \mathrm{Nm}$ \\
V-type IPMSM & $10.73 \%$ & $6.13 \mathrm{Nm}$ \\
\hline
\end{tabular}

The results reveal that it is difficult to apply the U-type to a multi-pole model because as the number of poles increases, the pole pitch that can be used per pole is limited; therefore, it is structurally difficult to use the U-type in multiple poles.

$$
T_{\text {ripple }}=\frac{T_{\max }-T_{\min }}{T_{\text {avg }}} \times 100[\%]
$$

Figure 4 shows the magnetic flux density saturation level under the rated load for each rotor shape. The maximum magnetic flux density saturation level at the teeth and yoke of the stator is approximately $1.6 \mathrm{~T}$, and the saturation level at the shoe end is $1.8 \mathrm{~T}$. In addition, it is observed that the end of the permanent magnet in the rotation direction is saturated to a minimum of $1.8 \mathrm{~T}$ or higher due to the movement of the magnetic neutral point according to the rotation direction. The torque ripple can be reduced by minimizing the area of magnetic flux density saturation.

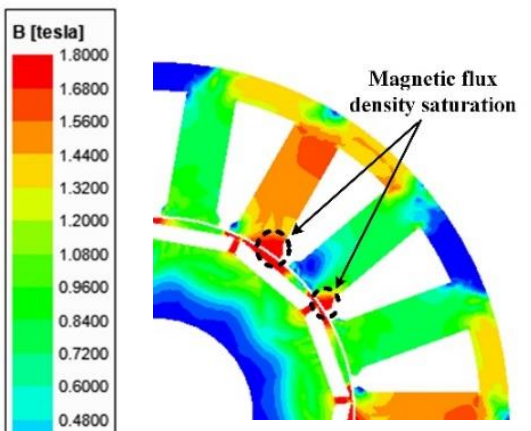

(a)

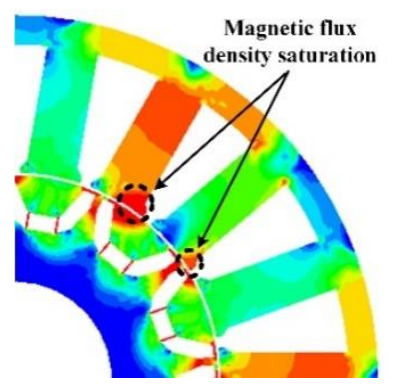

(b)

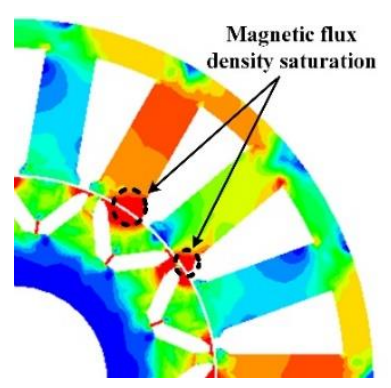

(c)

Figure 4. Magnetic field distribution at $1350 \mathrm{rpm}$. (a) Bar-type IPMSM; (b) U-type IPMSM; (c) V-type IPMSM.

Figure 5 shows the analysis of the no-load back-EMF THD of the three models. All three models have large 5th and 7th harmonic components. When the fundamental wave rotates in the $\omega t$ direction, the 5th harmonic rotates in the opposite direction of the fundamental wave rotation $-\omega t$, and the 7 th harmonic rotates in the same direction as the fundamental wave rotation direction $\omega t$, as follows:

$$
\begin{aligned}
& f_{5}=\frac{3}{2} F_{m 5} \sin (5 \theta-\omega t)[A T] \\
& f_{7}=\frac{3}{2} F_{m 5} \sin (7 \theta+\omega t)[A T]
\end{aligned}
$$




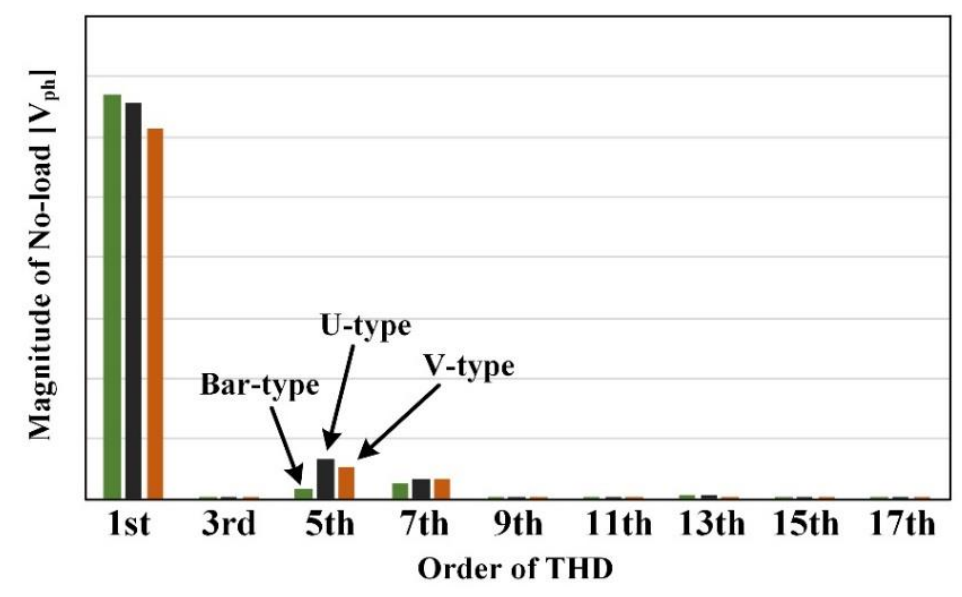

Figure 5. Total harmonic distribution at no-load back electromotive force (back-EMF).

The bar-type THD seems relatively lower than the other types, but it is confirmed that it has poor cogging torque characteristics, as shown in Table 2. It cannot be determined that the THD and cogging torque are unconditionally proportional. A comparison of the three basic models confirmed that the V-type model can minimize the torque ripple, cogging torque, and THD.

\section{Design of Barrier Shape to Reduce Torque Ripple}

To analyze and reduce the torque ripple according to the barrier shape, the design parameters were set as shown in Figure 6. The torque ripple was reduced using the experimental design method, RSM. The conventional optimization method was able to monitor the response to one variable [31]. However, RSM can obtain an optimal response for more than two variables. Accordingly, RSM can obtain more efficient and accurate optimization results than conventional optimization methods. In particular, the central composite design (CCD) of RSM was applied. Since the CCD contains an embedded factorial or fractional factorial design with center points that is augmented with a group of star points that allow an estimation of curvature, which depends on certain properties required for the design.

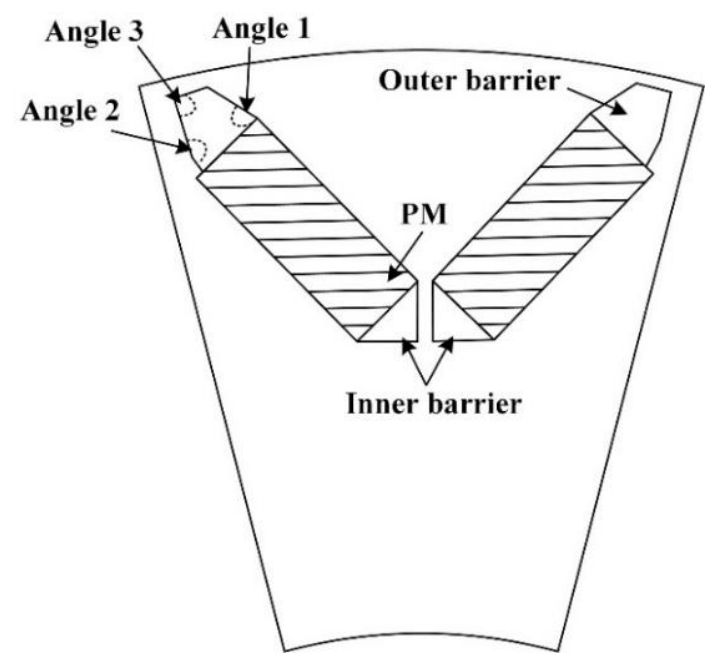

Figure 6. Design variables of rotor.

Figure 7 shows the contour plots of the average torque and torque ripple for the barrier angle. For reference, the shape of the inner barrier of the rotor was analyzed, but the inner barrier did not affect the output characteristics. The level of influence contributes to the average torque and torque ripple. The average torque should be as large as possible, and 
the torque ripple should be as small as possible. Comparing the average torque and torque ripple characteristics according to each barrier angle reveals that the torque ripple may increase when the barrier is designed in the direction of increasing the average torque, and the torque ripple tends to decrease when the barrier is designed in the direction of decreasing average torque. Therefore, it is necessary to design in the area where the green areas of the average torque and torque ripple graph overlap. After optimizing the outer barrier, which are Angle 1 of $14^{\circ}$, Angle 2 of $-0.1^{\circ}$, and Angle 3 of $3^{\circ}$, the average torque obtained is $109.9 \mathrm{Nm}$. The torque ripple is $7.57 \%$ which is a $7 \%$ reduction, as shown in Figure 8. In addition, with the optimization of the barrier shape, the torque max value is not significantly different, but the torque ripple peak to peak is reduced. To further reduce the torque ripple, the wedge shape applied to the stator shoe, such as the step skew, will be discussed in Section 4.
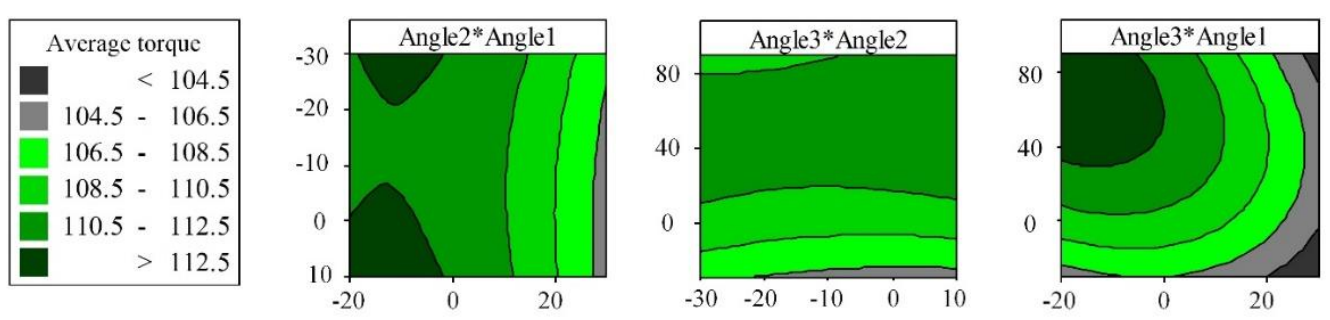

(a)
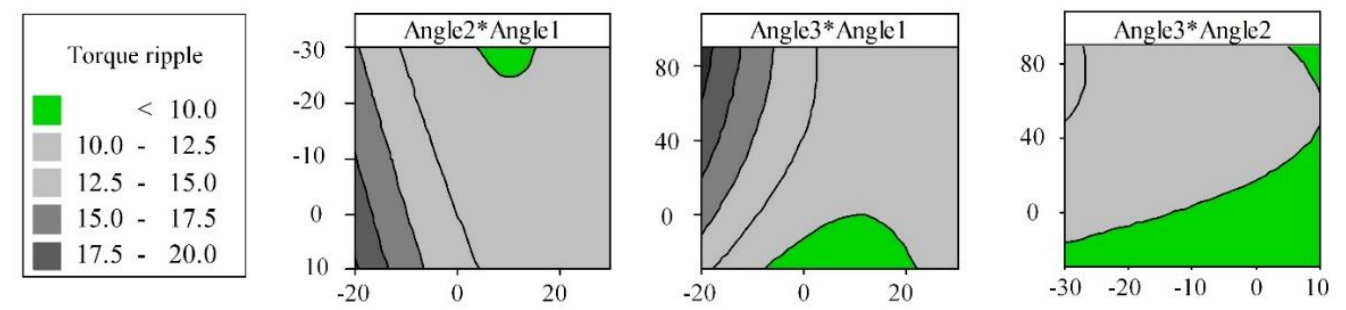

(b)

Figure 7. Contour plot according to design parameters by 2D finite element analysis (FEA) result: (a) average torque; (b) torque ripple.

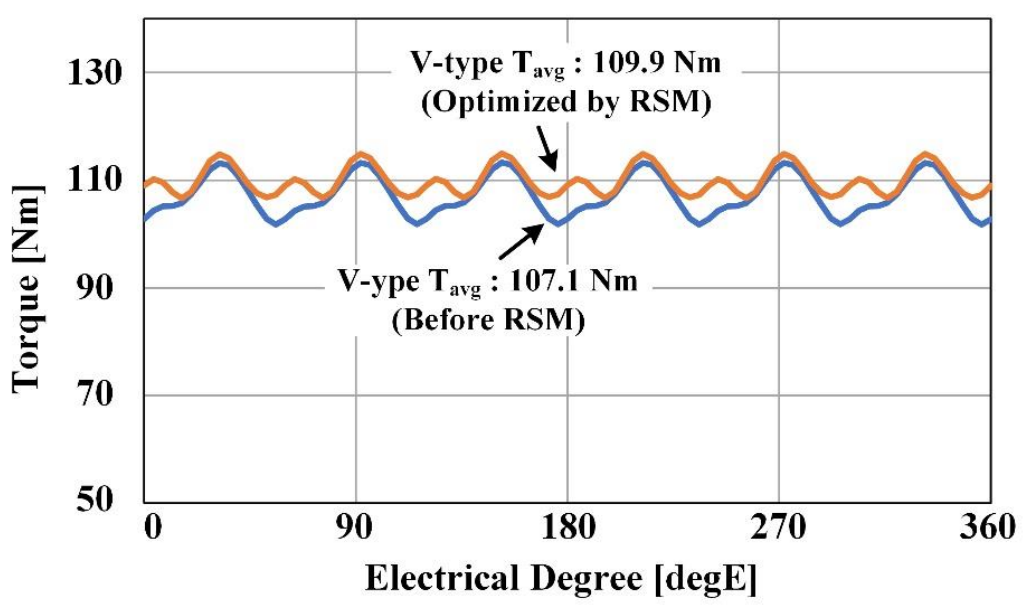

Figure 8. Torque wave form with the optimized barrier angles. 


\section{Design and Analysis of Wedge Skew}

\subsection{Conceptual Idea of Wedge Skew}

In general, continuous skew is applied to the stator or rotor or the 3-layer, 4-layer, or 5-layer step skew is applied to the rotor. However, it is difficult to apply step skew to a stator because of windings. In this section, a wedge shape is applied to the stator shoe part-similar to a step skew-to reduce the torque ripple. The output characteristics of the spoke-type PMSM with a wedge shape have been verified experimentally [21].

Figure 9 shows three conceptual diagrams for wedge skew. Wedge skew is a method in which a groove is made in a circular shape in the stator shoe, and the air gap length between the rotor and the stator can be partially lengthened from the viewpoint of the magnetic equivalent circuit. However, when the region in which the saturated magnetic flux density is removed, the air gap magnetic reluctance becomes uniform; the air gap magnetic flux density can also be expected to be more uniform.

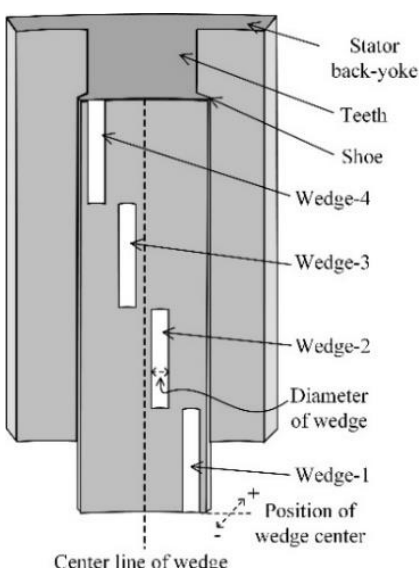

(a)

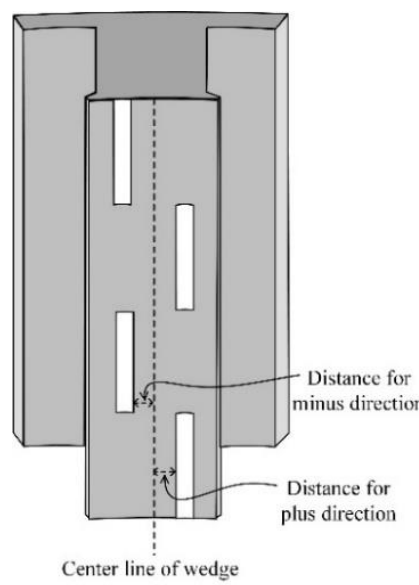

(b)

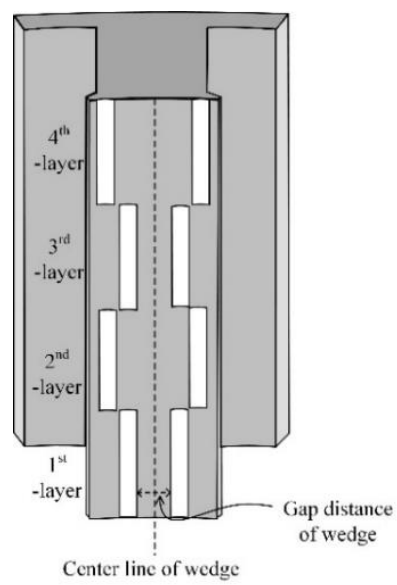

(c)

Figure 9. Schematic of the wedge skew: (a) A-type; (b) B-type; (c) C-type.

\subsection{Result of Torque Ripple Characteristic with the Wedge Skew by 3D Finite Eelement Analysis}

In the A-type and B-type, the shape of the wedge skew is arranged in only one direction. In the case of the C-type, the shape of the wedge skew is symmetrically arranged in a bidirectional manner based on the center line of the wedge. Therefore, when considering the rotation direction of the motor, the C-type can obtain the same torque ripple characteristics in both directions. Figure 9c shows the four-layer wedge skew, and the three-layer or five-layer wedge skew were also analyzed by three-dimensional finite element analysis (3D FEA).

Prior to discussion about the results of the wedge skew application, the average torques of 2D and 3D FEA of the final model in Section 3 were $109.9 \mathrm{Nm}$ and $109.1 \mathrm{Nm}$, respectively. The result of the wedge skew shows the C-type has better torque ripple characteristics than the A-type and B-type. Figure 10 shows the results of a more detailed analysis of the C-type according to various layers. The results also show the characteristics of average torque and torque ripple according to the number of layers, wedge skew diameter, and the depth of the wedge skew. The wedge skew depth is determined by the position of the wedge center. Before obtaining the analysis results in Figure 10, an analysis was conducted to determine the optimal location according to the wedge locations for all layers. To minimize the torque ripple while retaining an average torque greater than $106.5 \mathrm{Nm}$, each green area should be overlapped in the average torque and torque ripple graphs in Figure 8. The design points are marked in the graphs. In the case of the 3-layer wedge skew, the analysis was performed in conditions where the gap distance of wedge-1 was $4.01 \mathrm{~mm}$, gap distance of wedge- 2 was $6.68 \mathrm{~mm}$, and gap distance of wedge- 3 was $9.35 \mathrm{~mm}$. For the 4-layer wedge skew, the analysis was conducted in conditions where 
the gap distance of wedge- 1 is $10.68 \mathrm{~mm}$, gap distance between wedge- 2 and wedge- 3 is $21.36 \mathrm{~mm}$, and gap distance of wedge- 4 is $18.69 \mathrm{~mm}$.
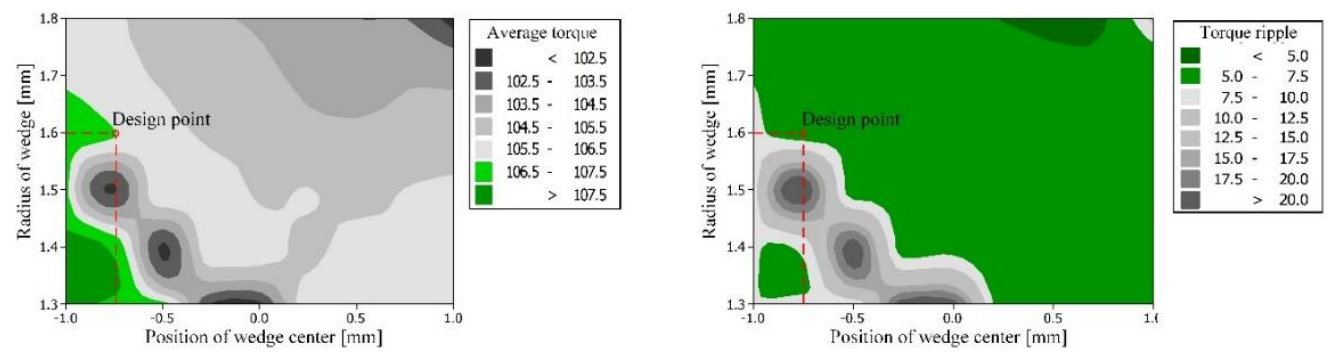

(a)
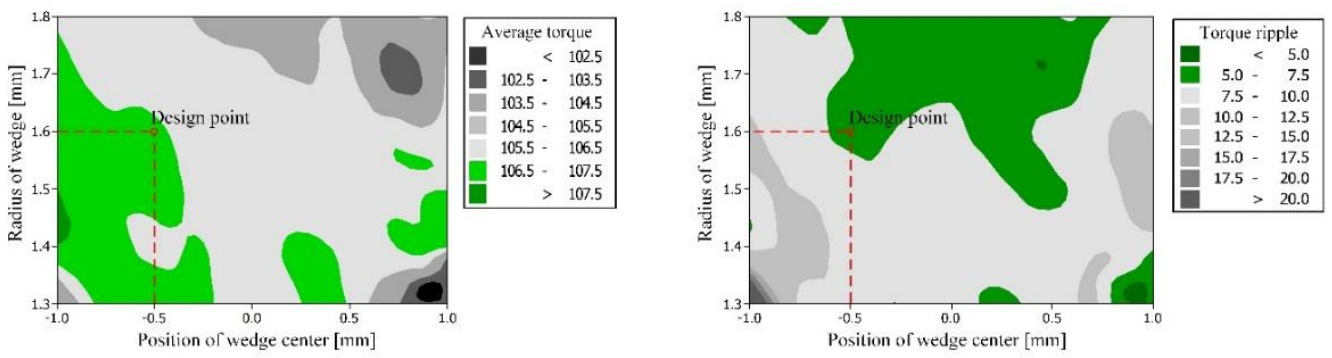

(b)
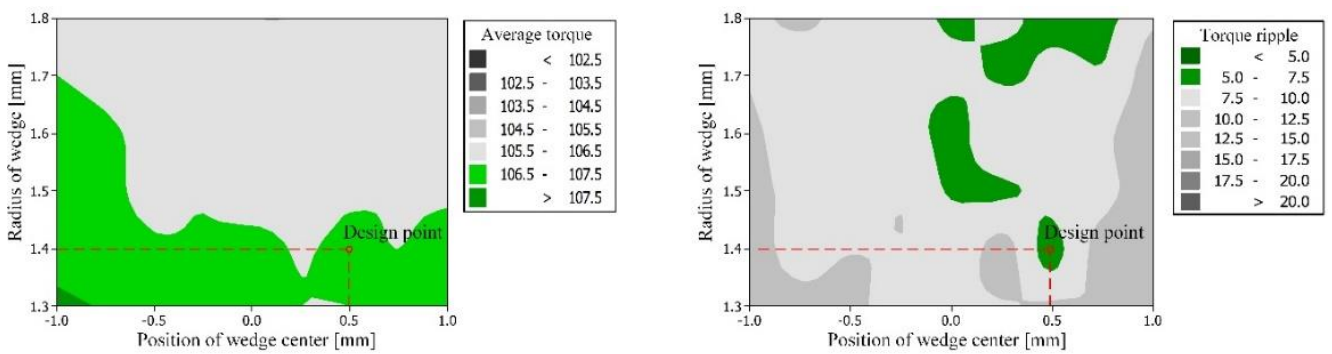

(c)

Figure 10. Contour plot of average torque and torque ripple characteristics by wedge skew parameter by 3D FEA: (a) 3 layers; (b) 4 layers; (c) 5 layers.

Analysis of the 5-layer wedge skew was performed in conditions where the gap distance of wedge- 1 was $5.34 \mathrm{~mm}$, the gap distance between wedge- 2 and wedge- 3 was $10.68 \mathrm{~mm}$, and the gap distance of wedge- 4 was $5.34 \mathrm{~mm}$. These conditions are design variables in which the torque ripple is minimized while satisfying the required average torque via 3D FEA.

To increase the average torque, the wedge skew should be located near the air gap (minus direction of the wedge center position), and the diameter should be as small as possible. Conversely, to reduce the torque ripple, the wedge skew must be located far from the air gap, and the diameter must be large. To improve both the average torque and reduce the torque ripple, it is necessary to identify a condition that satisfies both conditions in the contour plot.

The analysis results for the wedge skew shape are shown in Table 3. The A-type was arranged in a 4-layer wedge skew with a constant spacing between the $1.4 \mathrm{~mm}$ radii of the wedges; the required average torque was satisfied, and the minimum torque ripple was obtained. In the case of the B-type, the lowest torque ripple was obtained when the wedge radius was $1.4 \mathrm{~mm}$, the distances of wedge- 1 and wedge- 3 were $+11.35 \mathrm{~mm}$, and the distances of wedge- 2 and wedge- 4 were $+5.67 \mathrm{~mm}$ from the center line of the wedge. 
As a result of the shape of the B-type, the wedge skew is located on one side; therefore, it can be seen that the wedge skew is also related to the direction of the rotation. Among the 5 types of wedge skew, the model capable of minimizing the torque ripple while satisfying the required average torque is a C-type 4-layer wedge skew with a wedge skew radius of $1.6 \mathrm{~mm}$ and a position is $-0.5 \mathrm{~mm}$. Figure 11 shows a 3D model of a C-type 4-layer wedge skew. The 3D mesh of the model before and after skew wedge application are shown in Figure 12. Figure 13 shows the torque waveform of the final model. The average torque is $106.6 \mathrm{Nm}$, and the torque ripple is $6.84 \%$, which is $36 \%$ less than that of the basic model.

Table 3. Comparison of torque characteristics at $1350 \mathrm{rpm}$ with the wedge skew.

\begin{tabular}{ccc}
\hline Type & $\begin{array}{c}\text { Average Torque } \\
\mathbf{( N m )}\end{array}$ & $\begin{array}{c}\text { Torque Ripple } \\
\mathbf{( \% )}\end{array}$ \\
\hline A-type & 107.5 & 8.49 \\
\hline B-type & 107.3 & 7.56 \\
\hline C-type (3 layers) & 106.5 & 8.36 \\
\hline C-type (4 layers) & 106.6 & 6.84 \\
\hline C-type (5 layers) & 106.5 & 7.30 \\
\hline
\end{tabular}

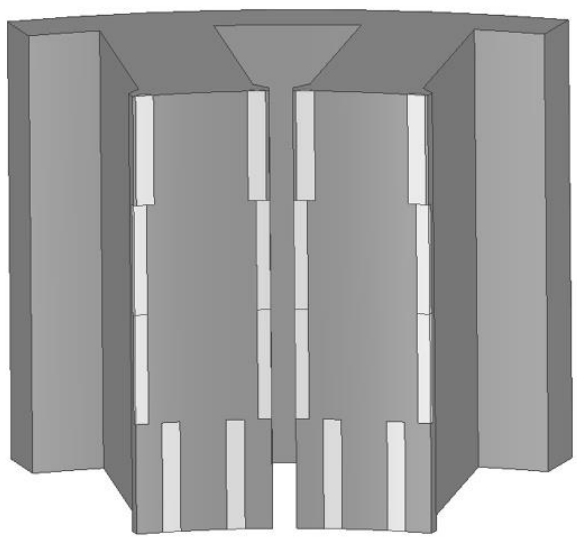

(a)

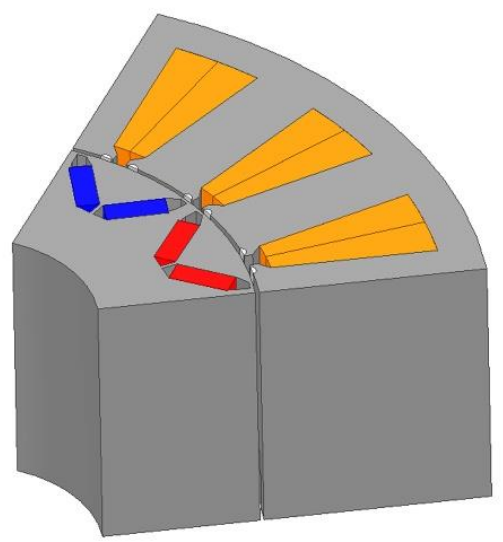

(b)

Figure 11. 3D periodic model with the 4-layer wedge skew with radius of $1.6 \mathrm{~mm}$ and position of $0.5 \mathrm{~mm}$ : (a) stator; (b) stator and rotor.

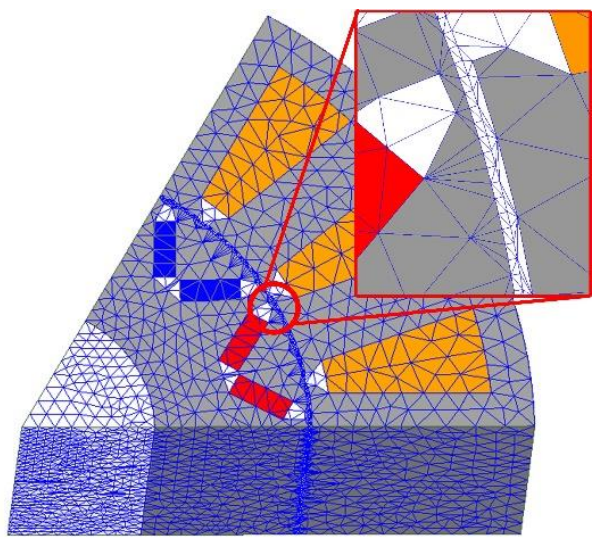

(a)

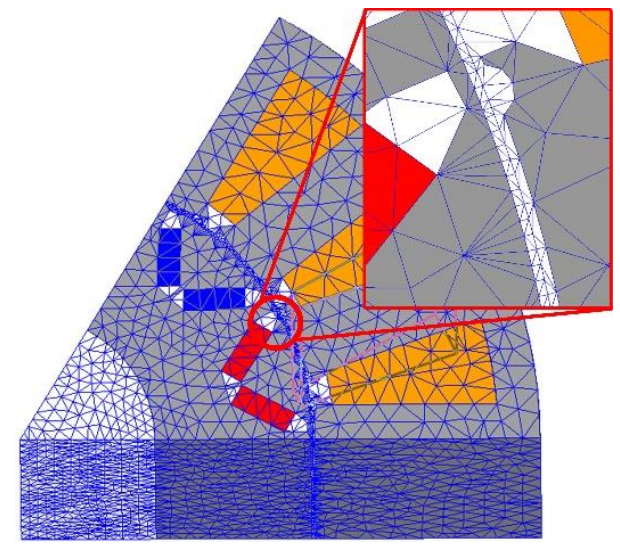

(b)

Figure 12. 3D mesh: (a) no wedge skew model; (b) wedge skew model. 


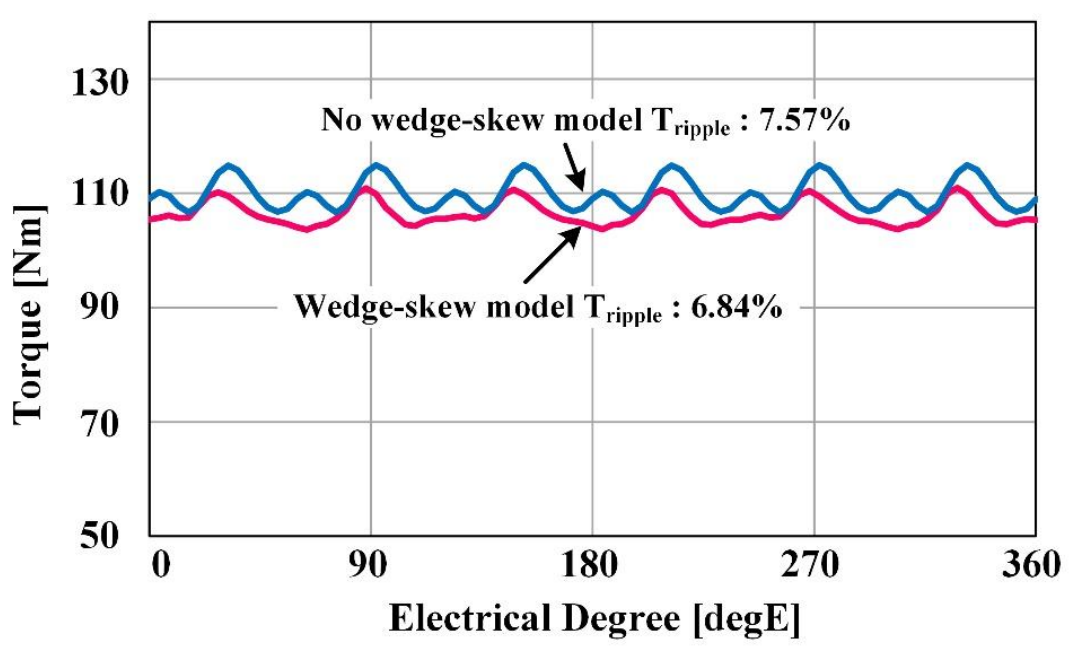

Figure 13. Torque wave form of final model.

To make the wedge skew on the stator shoe part, the stator mold frame may be constructed into three shapes according to the position of the wedge skew or a wedge skew shape may be produced on the shoe part by postprocessing after constructing the stator.

Figure 14b shows the magnetic flux density distribution of the final model. Compared to the basic model, the saturation area of the magnetic flux density is reduced, and accordingly, the torque ripple is reduced. The output characteristics of the wedge skew applied model and the basic model are shown in Table 4. It was confirmed that the torque ripple and no-load THD were reduced by applying wedge skew.

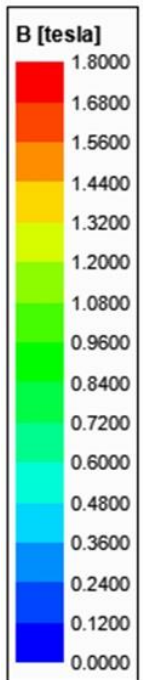

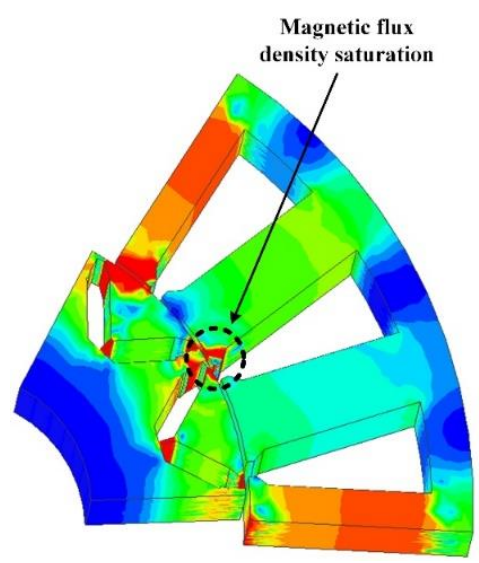

(a)

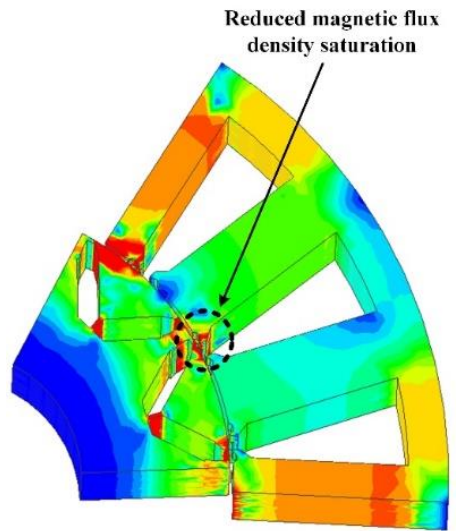

(b)

Figure 14. Comparison of magnetic density field distribution at $0 \mathrm{~ms}$. (a) No wedge skew model; (b) wedge skew model.

Table 4. Output characteristic of basic model and wedge skew model.

\begin{tabular}{cccccc}
\hline Model & $\begin{array}{c}\text { Average } \\
\text { Torque (Nm) }\end{array}$ & $\begin{array}{c}\text { Torque } \\
\text { Ripple (\%) }\end{array}$ & $\begin{array}{c}\text { Cogging } \\
\text { Torque (Nm) }\end{array}$ & $\begin{array}{c}\text { THD } \\
(\mathbf{\%})\end{array}$ & $\begin{array}{c}\text { Back-EMF } \\
(\mathbf{V} \text { ph) }\end{array}$ \\
\hline Basic model & 107.1 & 10.75 & 6.13 & 10.1 & 43.4 \\
\hline Wedge skew model & 106.6 & 6.84 & 6.40 & 4.89 & 42.8 \\
\hline
\end{tabular}




\section{Conclusions}

This study shows an investigation on the torque ripple for EV or HEV motors. The $15 \mathrm{~kW}$ motor can be installed after P2. The P2 is positioned after the clutch of the HEV and can greatly affect the passenger comfort. For low torque ripple, 12-pole 18-slot fractional slot winding is adopted. To reduce the torque ripple by comparing the cogging torque, no-load back-EMF THD, and torque ripple for each rotor shape of the IPMSM, it was determined that the $\mathrm{V}$-type rotor is suitable. Because the torque ripple can be reduced according to the design of the rotor barrier shape, the experimental design method, RSM, is introduced, and the torque ripple is reduced by $7 \%$ via the barrier optimization design. Moreover, the additional torque ripple was reduced by applying the wedge skew shape to the stator shoe. When designing the wedge skew, the manufacturability and bidirectional rotation were considered. It is confirmed that the wedge skew shape has made magnetic flux density saturation low and reduced torque ripple by placing it in the stator shoe part. The torque ripple was further reduced by $9.6 \%$ by the wedge skew. The torque ripple is reduced by $36 \%$ compared to the basic model.

Author Contributions: Conceptualization and methodology, H.J.; validation, H.K.; formal analysis, H.J. and H.K.; investigation, H.J. and H.-J.L.; resources, H.-J.L.; data curation, H.J. and H.K.; writingoriginal draft preparation, H.J.; writing-review and editing, H.-C.L. and H.-J.L.; supervision, J.L.; project administration, J.L.; funding acquisition, H.-J.L. and J.L. All authors have read and agreed to the published version of the manuscript.

Funding: This research was funded in part by the Korea Agency for Infrastructure Technology Advancement (KAIA) grant funded by the Korea government Ministry of Ministry of Land, Infrastructure and Transport. (21CTAP-C157784-02) and in part by the Energy Efficiency \& Resources of the Korea Institute of Energy Technology Evaluation and Planning(KETEP) grant funded by the Korea government Ministry of Knowledge Economy (No. 2018201010633A).

Informed Consent Statement: Not applycable.

Data Availability Statement: Not applycable.

Conflicts of Interest: The authors declare no conflict of interest.

\section{References}

1. Xue, Q.; Zhang, X.; Teng, T.; Zhang, J.; Feng, Z.; Lv, Q. A Comprehensive Review on Classification, Energy Management Strategy, and Control Algorithm for Hybrid Electric Vehicles. Energies 2020, 13, 5355. [CrossRef]

2. Rao, Z.; Zhang, W.; Wu, G.; Zheng, J.; Huang, S. Characteristic Analysis and Predictive Torque Control of the Modular Three-Phase PMSM for Low-Voltage High Power Application. Energies 2020, 13, 5606. [CrossRef]

3. Chu, G.; Dutta, R.; Pouramin, A.; Rahman, M.F. Analysis of Torque Ripple of a Spoke-Type Interior Permanent Magnet Machine. Energies 2020, 13, 2886. [CrossRef]

4. Liu, H.C.; Kin, I.G.; Oh, Y.J.; Lee, J.; Go, S.C. Design of Permanent Magnet-Assisted Synchronous Reluctance Motor for Maximized Back-EMF and Torque Ripple Reduction. IEEE Trans. Magn. 2017, 53, 8202604. [CrossRef]

5. Wei, C.; Hofman, T.; Caarls, E.I.; Iperen, R.V. A Review of the Integrated Design and Control of Electrified Vehicles. Energies 2020, 13, 5454. [CrossRef]

6. Yang, T.; Kawaguchi, T.; Hashimoto, S.; Jiang, W. Switching Sequence Model Predictive Direct Torque Control of IPMSMs for EVs in Switch Open-Circuit Fault-Tolerant Mode. Energies 2020, 13, 5593. [CrossRef]

7. Seo, U.J.; Chun, Y.D.; Choi, J.H.; Han, P.W.; Koo, D.H.; Lee, J. A Technique of Torque Ripple Reduction in Interior Permanent Magnet Synchronous Motor. IEEE Trans. Magn. 2011, 47, 3240-3243. [CrossRef]

8. Dorrell, D.G.; Hsieh, M.F.; Knight, A.M. Alternative Rotor Designs for High Performance Brushless Permanent Magnet Machines for Hybrid Electric Vehicles. IEEE Trans. Magn. 2012, 48, 835-838. [CrossRef]

9. Dai, M.; Keyhani, A.; Sebastian, T. Torque Ripple Analysis of A Permanent Magnet Brushless DC Motor Using Finite Element Method. In Proceedings of the IEEE International Electric Machines and Drives Conference, Cambridge, MA, USA, 17-20 June 2001.

10. Tumbek, M.; Kesler, S. Design and Implementation of a Low Power Outer-Rotor Line-Start Permanent-Magnet Synchronous Motor for Ultra-Light Electric Vehicles. Energies 2019, 12, 3174. [CrossRef]

11. Zhu, S.; Chen, W.; Xie, M.; Liu, C.; Wang, K. Electromagnetic Performance Comparison of Multi-Layered Interior Permanent Magnet Machines for EV Traction Applications. IEEE Trans. Magn. 2018, 54, 8104805. [CrossRef] 
12. Hwang, M.H.; Lee, H.S.; Cha, H.R. Analysis of Torque Ripple and Cogging Torque Reduction in Electric Vehicle Traction Platform Applying Rotor Notched Design. Energies 2018, 11, 3053. [CrossRef]

13. Zhong, Z.; Jiang, S.; Zhou, Y.; Zhou, S. Active torque ripple reduction based on an analytical model of torque. IET Electr. Power Appl. 2017, 11, 331-341. [CrossRef]

14. Islam, R.; Husain, I.; Fardoum, A.; McLaughlin, K. Permanent-Magnet Synchronous Motor Magnet Designs With Skewing for Torque Ripple and Cogging Torque Reduction. IEEE Trans. Indust. Appl. 2009, 45, 152-160. [CrossRef]

15. Azar, Z.; Zhu, Z.Q.; Ombach, G. Influence of Electric Loading and Magnetic Saturation on Cogging Torque, Back-EMF and Torque Ripple of PM Machines. IEEE Trans. Mangn. 2012, 48, 2650-2658. [CrossRef]

16. Islam, M.S.; Mir, S.; Sebastian, T.; Underwood, S. Design Considerations of Sinusoidally Excited Permanent-Magnet Machines for Low-Torque-Ripple Applications. IEEE Trans. Indust. Appl. 2005, 41, 955-962. [CrossRef]

17. Baek, S.W.; Lee, S.W. Design Optimization and Experimental Verification of Permanent Magnet Synchronous Motor Used in Electric Compressors in Electric Vehicles. Appl. Sci. 2020, 10, 3235. [CrossRef]

18. Han, S.H.; Jahns, T.M.; Soong, W.L.; Guven, M.K.; Illindala, M.S. Torque Ripple Reduction in Interior Permanent Magnet Synchronous Machines Using Stators With Odd Number of Slots Per Pole Pair. IEEE Trans. Ener. Conver. 2010, 25, 118-127. [CrossRef]

19. Zohra, B.; Akar, M.; Eker, M. Design of A Novel Line Start Synchronous Motor Rotor. Electronics 2019, 8, 25. [CrossRef]

20. Ito, Y.; Akatsu, K. Minimization of torque ripple in an Inset type Magnet Reluctance Motor with square wave current. In Proceedings of the 2018 XIII International Conference on Electrical Machines (ICEM), Alexandroupoli, Greece, 3-6 September 2018.

21. Jang, H.; Oh, S.T.; Kim, H.; Jang, I.S.; Lee, J. Design and Analysis of a Novel Rotor Shape to Improve Power Performance. IEEE Trans. Appl. Supercond. 2020, 30, 5201304. [CrossRef]

22. Jahns, T.M.; Soong, W.L. Pulsating torque minimization techniques for permanent magnet ac motor drives-a review. IEEE Trans. Indst. Electr. 1996, 43, 321-330. [CrossRef]

23. Rao, J.; Gao, Y.; Li, D.; Qu, R. Performance Analysis of Interior Permanent Magnet Motor Using Overlapping Windings With Fractional Ratio of Slot to Pole Pair. IEEE Trans. Appl. Supercond. 2016, 7, 0610005. [CrossRef]

24. Sun, H.Y.; Wang, K. Space Harmonics Elimination for Fractional-Slot Windings with Two-Slot Coil Pitch. IEEE Access 2019, 7 , 106961-106972. [CrossRef]

25. Wu, Z.Z.; Zhu, Z.Q.; Zhan, H.L. Comparative Analysis of Partitioned Stator Flux Reversal PM Machines Having Fractional-Slot Nonoverlapping and Integer-Slot Overlapping Windings. IEEE Trnas. Enrgy Conver. 2016, 31, 776-788. [CrossRef]

26. Donato, G.D.; Capponi, G.; Rivellini, G.A.; Caricchi, F. Integral-Slot versus Fractional-Slot Concentrated-Winding Axial-Flux Permanent-Magnet Machines: Comparative Design, FEA, and Experimental Tests. IEEE Trans. Indust. Appl. 2012, 48, 1487-1495. [CrossRef]

27. EL-Refaie, A.M. Fractional-Slot Concentrated-Windings Synchronous Permanent Magnet Machines: Opportunities and Challenges. IEEE Trans. Indust. Electr. 2010, 57, 107-121. [CrossRef]

28. Wu, D.; Zhu, Z.Q. Design Tradeoff between Cogging Torque and Torque Ripple in Fractional Slot Surface-Mounted Permanent Magnet Machines. IEEE Trans. Magn. 2015, 51, 8108704. [CrossRef]

29. Wang, K.; Lin, H. Modular Permanent Magnet Synchronous Machine with Low Space Harmonic Content. Energies 2020, 13, 3924 [CrossRef]

30. Bianchi, N.; Bolognani, S.; Pre, M.D.; Grezzani, G. Design Considerations for Fractional-Slot Winding Configurations of Synchronous Machines. IEEE Trans. Indust. Appl. 2006, 42, 997-1006. [CrossRef]

31. Bezerra, M.A.; Santelli, R.E.; Oliveira, E.P.; Villar, L.S.; Excaleira, L.A. Response surface methodology (RSM) as a tool for optimization in analytical chemistry. Talanta 2008, 76, 965-977. [CrossRef] 